\title{
Special issue on Materials and Society: the Circular Economy SAM-13
}

Jean-Pierre Birat ${ }^{*}$

IF Steelman, Semécourt, France

Received: 5 January 2020 / Accepted: 10 January 2020

The 13th Society and Materials conference, SAM-13, took place in Pisa, Italy, on 20 and 21 May, 2019. The present issue of Matériaux \& Techniques collects a representative selection of 9 papers given at the conference, highlighting its main themes. These went through a peer review with the Journal.

The conference focused on contemporary and emerging issues related to materials and energy, with a strong emphasis on new methodologies, experimental approaches and interdisciplinarity, from hard sciences and engineering to social sciences and humanities.

The first two papers examine technical issues related to materials through unusual filters in industrial ecology or material processing, i.e. philosophy and epistemology:

- JP. Birat of IF Steelman [1] discusses the matter of the circular economy by considering that reused or recycled materials are akin to a palimpsest (an old manuscript that is erased and on which a new text is written) on the one hand and that the circular economy is a heterotopia (a space separated from usual physical space by specific rules, even though both do communicate) on the other hand. The method proves capable of discussing all the features of the circular economy in a compact manner and may be casting light on unexplored areas;

- H. Tveit and L. Kolbensein of NTNU [2] discuss the special status of silicon as a material by analyzing the specifics of its entropy function, which are definitely unique compared to those of a common metal. They go on to say that this makes the production of silicon fairly difficult on the one hand, what they call the hate relationship, and, on the other hand, transforms silicon into a material with outstanding properties and an especially social value, what they call the love relationship. Entropy, a very classical thermodynamic function, is thus used as a kind of metrics to analyze the social value of this particular material.

\footnotetext{
* e-mail: jean-pierre.birat@ifsteelman.eu
}

The next two papers illustrate how LCA methodology can be extended to reflect contemporary and pluridisciplinary issues:

- N. Iken, S. Morel and F. Aggeri of Renault and Mine ParisTech [3] developed an in-house methodology based initially on an LCC framework to examine the cost of various automobile systems (car and manufacturer's portfolio) and subsystems (parts) from the standpoint of different stakeholders, the car owner (cost of ownership), the car manufacturer (materials costs) and civil society (environmental cost). The usefulness of the tool inside Renault was further assessed by internal experts, especially in terms of decision making for improving design. Furthermore, the authors also conducted qualitative research on how these complementary standpoints could be integrated;

- Ann-Kathrin Briem, Thomas Betten, Daniel Wehner of the University of Stuttgart [4] explored the development and the potential of the personalization of $L C A$, in a societal context where "mass personalization" is replacing "mass production". A standard LCA would only deliver data and conclusions averaged over users, but it is now possible to collect individual data through agent-based modeling or big data analytics and then to feed back the conclusions in ways that are more relevant to the individual user.

A fifth paper deals with the material conundrum, an expression meaning that high-tech artefacts used to lower the environmental and societal footprint expressed in terms of GHG emissions usually call on very many rare, critical and specific materials that, therefore, raise a different kind of environmental challenge, i.e. material scarcity. J. F. Peters, M. Abdelbaky, M. Baumann, M. Weil of the Karlsruhe Institute of Technology [5] addressed a particular example of this issue: indeed, sodium-ion batteries would be superior to lithium-ion batteries in terms of the availability of sodium vs. lithium, except that they need amorphous carbon anodes rather than graphite ones. Such anodes are produced one at a 


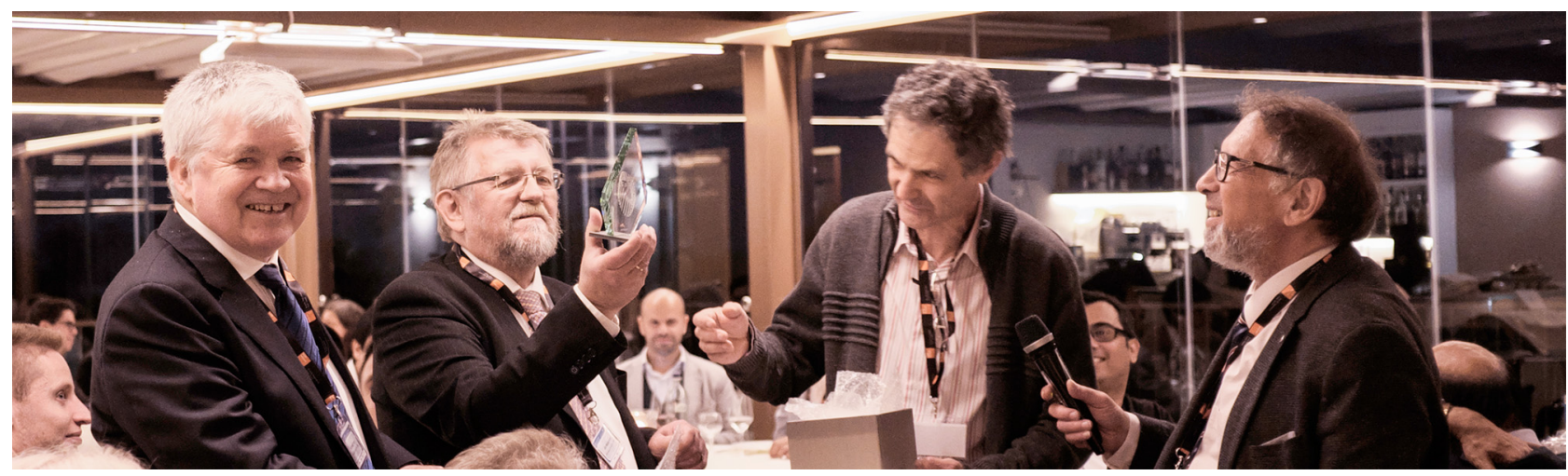

Fig. 1. Halvard Tveit, Leiv Kolbeinsen receiving the award from Mauro Chiappini. Jean-Pierre Birat, right.

time for experimental purposes only today and, therefore, the details of industrial production are not available from the literature: the paper proposes to generate an LCI from modeling the process route for making them, an approach usually applied to describe future, not-yet existing technologies. The authors conclude that among the various options to make the anodes, using apple pomace as a carbon source delivers the "greener" solution.

The next two papers, which are complementary, explore the concept of industrial symbiosis from the standpoint of the steel industry:

- S. Rosendahl, K. Lundkvist, B. Haase, J. Stemne, L. Andersson, R. Eriksson of Swerim, Höganäs, SSAB, Boliden and Jernkontoret [6] have considered, from a very general and systemic standpoint (physical, regulatory, business, motivation and society), how residual materials from a steel mill, also called by-products (slag, dust and sludge), which would normally end up as waste, can be delivered to other industries as raw materials. They have developed a methodology to be implemented in collaborative work between the supplier and the recipient of the material;

- K. Lundkvist, S. Rosendahl, E. Sandberg, B. Haase, J. Stemne, P. Peltola, R. Eriksson of the same companies [7] carried out a case study, based on the previous methodology. They showed that using a cocktail of coproducts from a series of industrial symbiosis partners, which would exchange material in both directions, leads to solutions that make sense from the various standpoints of the study (technical, economic, societal): the highervalue materials would in effect pay for the lower-value ones; the whole system, though, intrinsically participates in the solution.

The last two papers deal with technical work carried out in the steel industry, which creates social value in a more classical, engineering-style way: it solves problems, minimizes energy and environmental footprints and cuts costs:

- A. Maddaloni, R. Matino, I. Matino, S. Dettori, A. Zaccara, V. Colla of Scuole Superiore Sant'Anna [8] propose a series of computational models to optimize the utilization of surplus gas in a steel mill. It uses state-ofthe-art, non-convex quadratically constrained quadratic programing (QCQP);
- M. De Santis, N. De Santis, D. Fera, R. Tonelli of Rina Consulting and Colakoglu Metalurji [9] developed a CFD model of mixing in the tundish of a Continuous Caster during ladle change in order to minimize downgraded material on slabs casts during that unsteady-state period. The environmental benefit is increased materials efficiency.

The 2019 Jean-Sébastien Thomas Prize for the best paper given in the SAM-14 conference was attributed to the second article by Tveit and Kolbeinsen [2]. The award ceremony is shown in Figure 1.

The program of the conference is given in the appendix, in order to show that the selected papers are indeed representative of the whole event.

\section{Appendix: Program of SAM-13}

Welcome address: Prof. Sabina NUTI, Scuola Superiore Sant'Anna, Italy, Jean-Pierre BIRAT, IF Steelman, France

\section{Session 1: Sustainability, circular economy and eco-design}

\section{Chairman: Dominique MILLET, EcoSD, France}

- Keynote Lecture: Reflections on the importance of metrics in moving towards a sustainable society, Karl BUTTIENS, ArcelorMittal, Belgium

- Are circular economy solutions beneficial by definition? G. GARAVINI, Ecoinnovazionne SRL, Italy

Case study of industrial symbiosis for improved residual material utilization in the steel industry, K. LUNDKVIST, Swerim AB, Sweden

- From titanium scrap to high-value powders, N. MCDONALD, MetaFensch, France

- Value retention options in the Circular Economy: issues and challenges of LED lamps preprocessing, S. RAHMAN, University of Technology of Troyes, France

- How effective is reuse as a circular economy strategy? Assessment of the potential environmental benefits of second-hand consumption, F. REALE, Ecoinnovazionne SRL, Italy

ATISOL C2C-Ecodesign of a "vapour and air barrier membrane" made of renewable materials, S. GROSLAMBERT, University of Liège, Belgium 
- A quadratic programming model for the optimization of off gas network in integrated steelworks, A. MADDALONI, Scuola Superiore Sant'Anna/TeCIP, Italy

- How to generate and assess eco-innovative ideas in early design phases? O. PIALOT, QUARTZ/Supméca, France

\section{Session 2: Energy, climate and mobility}

Chairman: Jan BOLLEN, ArcelorMittal, Belgium

- Keynote Lecture: The role of Tuscany in the historical development of steel and metal industries, Renzo VALENTINI, Pisa University, Italy

- Life Cycle Assessment of Fluctuating Electricity Demand, J. WALZBERG, Polytechnique Montréal, Canada

- Product environmental footprint of an innovative technology for primary aluminum production, L. ZANCHI, Ecoinnovazionne, Italy

- Design for recyclability-challenges, limits 83 need for action on the way towards a circular battery economy, J. PETERS, KIT, Germany

- An optimized LCA approach to evaluate prospective grids, H. ELZEIN, Polytechnique Montréal, Canada

- A preliminary study for monetarizing life cycle assessment impacts of battery electric vehicles, J. GARCIA, PSA, France

- Study of parameter uncertainty in the automotive industry, J. RIVERA, ArcelorMittal, France

- Towards a sustainable material choice in the automotive industry, N. IKEN, Renault, France

- Resource demand for the mobility transition-batteries for bus and autonomous mini bus vehicles, M. WEIL, KIT, Germany

\section{Session 3: Critical materials \& MFA}

Chairman: Ichiro DAIGO, Tokyo University, Japan

- Keynote Lecture: Toward environmentally sustainable patterns of resource consumption and production, Kenichi NAKAJIMA, National Institute For Environmental Studies, Japan

- Resource paradox problem revealed by Total Material Requirement, E. YAMASUE, Ritsumeikan University, Japan

- SURFER - What is the burden of raw materials requirements to achieve the French energy transition? F. LAI \& F. LAURENT, BRGM, France

- Economic Feasibility of Recycling Rare Earth Oxides from Lighting Technologies, Y. QIU, University of Santa Barbara, Unite States

- The influence of stock dynamics on new technology penetration, R. BILLY, NTNU, Norway

- Material Flow Analysis Around The World: Perspectives And Limitations For Decision-Maker, A. THEVENOT, CyVi / Université de Bordeaux, France

\section{Session 4: Social challenges and responsible research \& innovation}

Chairman: Kathie BIRAT, Lorraine University, France

- Keynote Lecture: Positive Business Model: creating value with environmental and social product quality, Béatrice BELLINI, Université Paris Nanterre, France

- Palimpsest and heterotopia, as metaphors of the circular economy, J.-P. BIRAT, IF Steelman, France

- Could we talk of "Responsible materials"? A. DECLICH, Knowledge \& Innovation, Italy

- Modeling the Circular Economy in Environmentally Extended Input-Output Tables: methods, software and case study, F. DONATI, Leiden University, Netherlands

- The (love 83 hate) role of entropy in process metallurgy, H. TVEIT \& L. KOLBEINSEN, NTNU, Norway

- Greening the cement sector: a POLES model-based approach, S. MIMA, Université de Grenoble, France

- Finding universally applicable indicators for sustainable resource management: a comparison of circularity and statistical entropy, J. TANZER, TU Wien, Austria

- Public and societal engagement: good practices for co-creation of research and innovation outcomes, H. THRONE-HOLST, OsloMet University, Norway

\section{Session 5: ROBOARSH}

Chairman: Barbara FORNAI, Scuola Superioe Sant'Anna, Italy

- Keynote Lecture: Socio-Digital Transformation: Combining Industry 4.0 with Qualification 4.0, Antonius SCHRÖDER, Technische Universität Dortmund, Germany

- A robotic workstation designed for harsh environmental conditions to improve safety in the steel industry, V. COLLA, Scuola Superioe Sant'Anna, Italy

- New Human-Robot Interaction: From Operator to Supervisor, M. KOHLGRÜBER, SFS Dortmund, Germany

- Radio-frequency sensor for flux powder thickness measurement in billet / blooms continuous casting mould, F. MACCI, RINA Consulting, Italy

- A geometric and thermal measurement system for the dimensional control of blooms section, M. VEZZOLA, BM Group, Italy

\section{Posters}

- Economic and ecological assessment of different stationary batteries using different energy to power ratio, M. BAUMANN, KIT, Germany

- Graphene oxide quantum dots synthesized from biomass wastes: white light emitting material in the solid state, J.J. GAUMET, University de Lorraine, France 
- Revegetation of a temporary constructed wetland created for securing a landfill area, V. GIANNINI, Scuola Superiore Sant'Anna, Italy

- A New Data Collection Approach for Material Flow Analysis and Application in Railway Infrastructures in France, M. IMRAN, UTT, France

- Environmental assessment of hard carbon anode materials for sodium-ion batteries, J. PETERS, KIT, Germany

- Optimization approach for attractive and sustainable products, TCHERTCHIAN, Université de Toulon, France

- Social sustainability assessment of technologies for the energy transition-focus societal acceptance, M. WEIL, KIT, Germany

- The anthropogenic neodymium cycle in Europe. Stock, flows and recycling potentials of the "new twin", L. CIACCI, University of Bologna, Italy

- Governance of emerging technologies: the nanolabel risk management and communication approach for nanomaterials, F. BOCCUNI, INAIL, Italy

- Personalized life cycle assessment-reflecting individuality within the methodological framework, A-K. BRIEM, University of Stuttgart, Germany

- Computational fluid dynamics model-based online tool to optimize slab cut after steel intermixing in CC slabs, M. DE SANTIS, RINA Consulting, Italy

- Analysis of a controversy for education to sustainable and acceptable processes, products and services, A. DELEBARRE, Mines ParisTech, France and G. WEI, SJTU ParisTech Elite Institute of Technology, China

- The steel plant: the heart of an industrial symbiosis project, L. DI SANTE, RINA Consulting, Italy

- Service-learning as an opportunity to introduce sustainability competences in engineering degrees, T. GURAYA, Jaume I University, Spain

- Eco-optimization of a carsharing product-service system, O. GUYON, PSA, France

- A New Vision for Refractory Designing, D. OLEVANO, RINA Consulting, Italy

- Establishing an industrial symbiosis-key factors and time aspects in steel industry, S. ROSENDAHL, Swerim $\mathrm{AB}$, Sweden
- Responsible research and innovation: analyzing costs and benefits of RRI implementation in industrial context, D. PIMPONI, Italian Association for Industrial Research, Italy

- LCI analysis considering recycling, I. DAIGO, University of Tokyo, Japan

\section{References}

1. J.-P. Birat, Palimpsest and heterotopia, as metaphors of the Circular Economy, Matériaux \& Techniques 107, $505(2019)$

2. H. Tveit, L. Kolbeinsen, The (love \& hate) role of entropy in process metallurgy, Matériaux \& Techniques 107, 506 (2019)

3. N. Iken, S. Morel, Towards a sustainable material use in the automotive industry: Life Cycle Costing and socio-technical approach to material use, Matériaux \& Techniques 107, 504 (2019)

4. A.-K. Briem, T. Betten, D. Wehner, Personalized life cycle assessment-reflecting individuality within the methodological framework, Matériaux \& Techniques 107, 507 (2019)

5. J.F. Peters, M. Abdelbaky, M. Baumann, M. Weil, A review of hard carbon anode materials for sodium-ion batteries and their environmental assessment based on process modeling, Matériaux \& Techniques 107, 503 (2019)

6. S. Rosendahl, K. Lundkvist, B. Haase, J. Stemne, L. Andersson, R. Eriksson, Establishing an industrial symbiosis - key factors and time aspects in steel industry, Matériaux \& Techniques 107, 508 (2019)

7. K. Lundkvist, S. Rosendahl, E. Sandberg, B. Haase, J. Stemne, P. Peltola, R. Eriksson, Case study of industrial symbiosis for improved residual material utilisation in the steel industry, Matériaux \& Techniques 107, 509 (2019)

8. A. Maddaloni, R. Matino, I. Matino, S. Dettori, A. Zaccara, V. Colla, A quadratic programming model for the optimization of off-gas network in integrated steelworks, Matériaux \& Techniques 107, 502 (2019)

9. M. De Santis, N. De Santis, D. Fera, R. Tonelli, Online tool based on tundish steel CFD model to monitor and minimize steel intermix in CC slabs, Matériaux \& Techniques 107, 510 (2019)

Cite this article as: Jean-Pierre Birat, Special issue on Materials and Society: the Circular Economy SAM-13, Matériaux \& Techniques 107, $501(2019)$ 